\title{
Technological Advance in Cooling Systems at U.S. Power Plants
}

\author{
Allen Bellas \\ Duane Finney \\ Ian Lange
}

Stirling Economics Discussion Paper 2011-05

March 2011

Online at

http://www.management.stir.ac.uk/research/economics/workingpapers 
Technological Advance in Cooling Systems at U.S. Power Plants Allen Bellas*, Duane Finney*, and Ian Lange*

Prior to adoption of the 1972 Clean Water Act (CWA) most U.S. power plants used once-through cooling water systems that discharged large quantities of warm water and resulted in significant amounts of thermal pollution in neighboring bodies of water. The CWA essentially mandated recirculating systems for most new facilities. This paper investigates whether there was either cost-saving or performance enhancing technological advance in cooling systems and how these advances are related to imposition of the CWA.

*Metropolitan State University, 1501 Hennepin Ave, Minneapolis, MN 55403;

allen.bellas@metrostate.edu and finndu@go.metrostate.edu

Division of Economics, University of Stirling, Stirling FK9 4LA, UK; i.a.lange@ stir.ac.uk (Corresponding Author)

Keywords: Electricity Generation, Water Cooling: Innovation, Environmental Policy JEL Codes: Q52, Q40, L51 


\section{Introduction}

Thermal electrical generating plants use cooling systems to control the heat of combustion and increase net power output. Prior to adoption of the U.S. Clean Water Act (CWA) in 1972, most power plants were constructed with once-through cooling systems that took in and discharged large amounts of cooling water and resulted in significant temperature increases in their neighboring bodies of water. The increased temperatures of the bodies into which plants discharged their cooling water caused changes in their ecosystems that could be called thermal pollution damage. The Clean Water Act used a technology standard which essentially required that most new plants be built with recirculating cooling systems, which reuse cooling water and result in far less thermal pollution.

Whether the instrument used to reduce thermal pollution has hindered technological advance is unknown. This analysis tests whether the rate of technological advances that reduce the performance-adjust cost of installing a cooling system was impacted by the CWA. While previous research of this type has focused on air pollution control technology, this is the first analysis that the authors are aware of to focus on advances in water pollution control technology. Cost saving advances might be expected if the utilities that construct and operate power plants are cost-minimizing entities. In addition, as manufacturers of once-through systems faced increasing competition from recirculating systems, it is possible that this would spur increased technological advance as once-through cooling systems fought to maintain their position in the marketplace. 


\section{Background}

Among the environmental impacts of thermal electrical generating plants is the release of thermal energy with expelled cooling water. Power plants use cooling systems to control heat as well as to decrease the temperature and pressure of steam that has passed through a generating turbine, increasing the pressure differential across the turbine and improving the performance of the unit. The use of cooling systems can increase the power output of a boiler/generator combination. The environmental impact comes when the water used in the cooling system is released into a water source at a temperature far above the ambient temperature, an impact referred to as thermal pollution. Thermal pollution has the potential to severely impact ecosystems in the affected bodies of water, significantly affecting the mix of species found and potentially reducing the biodiversity of the area. Interestingly, the effects of thermal pollution can vary dramatically from location to location and from season to season, and are not unambiguously bad. In some circumstances, thermal emissions have been associated with increased biodiversity. However, to the extent that any ecological change from the natural state represents damage to at least one part of that ecosystem, thermal emissions could be considered damaging under any circumstances.

Prior to 1970 , most cooling systems used cooling water once and then discharged it back into the body of water from which it was drawn. These once-through systems generally take in massive amounts of water, straining and chlorinating it to prevent damage to cooling hardware. ${ }^{1}$ After the cooling water is treated, it is used to cool steam that has already passed through a generating turbine. The cooling process lowers the temperature of the steam, reducing its pressure. This

\footnotetext{
${ }^{1}$ Issues related to the design of these intake systems and their potential to kill many aquatic animals was the subject of a Supreme Court's Entergy v. Riverkeeper decision in April of 2009.
} 
reduced post-generation pressure steepens the pressure gradient across the turbine and allows more power to be produced with no associated increase in fuel consumption. The water, which has absorbed a significant amount of thermal energy, is then returned to the body of water from which it was drawn, causing a localized increase in the ambient water temperature. Typical temperature increases are $17^{\circ} \mathrm{F}$ for fossil fuel plants and $23^{\circ} \mathrm{F}$ for nuclear plants (EPRI, 2004).

The effects of these localized increases in water temperature vary tremendously depending on specific conditions. The discharge of a certain thermal volume ${ }^{2}$ of water might have a negligible impact if it is diffused broadly or put into a large or fast moving body of water but massive effects if discharged at one point or into a small, static body of water. In addition, warm water has less capacity for dissolved oxygen than does cold water. Because the natural processes that decompose organic waste consume oxygen, the warmer water released from cooling systems tends to encourage algal production compared to colder water. Different aquatic creatures prefer different temperatures. Releases of cooling water have the capacity to change the mix of creatures living near the effluent point and their level of activity. Whether this altered mix of species and behaviors necessarily constitutes pollution damage is debatable and may depend on local conditions and in which season the releases occur. Summer releases into already warm water may overheat some species or more fully deplete the oxygen in the water. Winter releases, however, might increase the diversity or the activity level of aquatic life, perhaps creating new recreational fishing opportunities. In the absence of any research to the contrary, we will assume that a greater thermal volume of discharge does, in fact, result in pollution damage and thus a reduction in thermal discharge is desirable, other things being the same.

\footnotetext{
${ }^{2}$ We will use the term thermal volume to be the product of the volume of water released and its increased temperature.
} 
The CWA effectively required new generating units to install closed circuit cooling systems, but offered the possibility of variances if the plant operator could demonstrate that a proposed oncethrough system would not adversely impact the local aquatic ecosystem. ${ }^{3}$ Plants that can successfully demonstrate that a once-through cooling unit, which may be much less expensive to install and operate than a closed circuit unit, will not compromise the existence of a balanced, indigenous population, may install a once-through system. This aspect of the CWA put closed cycle cooling systems into competition with once-through systems and essentially put pressure on designers of once-through systems to mitigate their environmental impact.

There is a large theoretical literature examining the effects of different environmental policy instruments on technological advancement and diffusion. A good review of the literature can be found in Jaffe et al (2002). Standard economic theory suggests that technology standards offer poor incentives for innovation in pollution control technology, especially if they are subject to change when technology advances. Several papers (Downing and White (1986); Millman and Prince (1989); Zerbe (1970); Requate and Unold (2003)) show that technological standards generally offer incentives for innovation that are smaller than those offered by market-based regulations. While the above findings assume a perfectly competitive supply of pollution control technology, David and Sinclair-Desgagne (2005) show that a monopolistic supplier of pollution control equipment will capture all of the rents from a polluting firm under a technology standard, implying that technologically adjusted costs will not fall over time.

\footnotetext{
${ }^{3}$ In the text of section $316(a)$ of the Act:

"With respect to any point source... whenever the owner or operator of any such source... can demonstrate... that any effluent limitation proposed for the control of the thermal component of any discharge from such source will require effluent limitations more stringent than necessary to assure the projection and propagation of a balanced, indigenous population of shellfish, fish, and wildlife in and on the body of water into which the discharge is to be made, the Administrator... may impose an effluent limitation... that will assure the protection and propagation of a balanced, indigenous population of shellfish, fish, and wildlife in and on that body of water."
} 
Several papers have investigated advances in air pollution equipment at thermal power plants. The most common equipment analyzed are flue-gas desulfurization (FGD) units, which are endof-pipe sulfur dioxide pollution control technologies. FGD systems were initially encouraged through an emissions standard in the 1970 Clean Air Act. The 1990 Clean Air Act initiated a system of tradable permits for sulfur dioxide emissions. Bellas (1998), Popp (2003), Lange and Bellas (2005) and Perino (2010) all use a hedonic price functions to model installation and/or operating costs of FGD systems. The results generally find that costs of FGD systems installed under an emissions standard regime did not decrease significantly over time, implying that the technology was stagnant. When the tradable permit scheme was initiated, FGD systems had a statistically significant drop in price. Perino (2010) finds evidence of price discrimination by FGD producers, suggesting that prices would have fallen more in the absence of market power. Bellas and Lange (2010) use a similar model for the installation and operating cost of flue-gas particulate (FGP) collectors, an end-of-pipe particulate pollution control technologies. Particulates have been regulated through an emissions standard since the 1970 Clean Air Act. Results match the predictions of David and Sinclair-Desgagne (2005) in that operating cost reductions are captured by the suppliers through increases in the purchase price. This analysis is the first, that the authors are aware of, that tests the relationship between environmental policy and technological advancement of water pollution control.

\section{Data Description}

The data come from the U.S. Energy Information Administration Form 767, an annual survey of U.S. steam-electric plants with ratings of 10 megawatts or greater. This form collects information 
on the design and operation of myriad aspects of the plants including the water cooling system(s). Because the information utilized here relates to the purchase of a water cooling system, only data from one year is needed. Data used in this analysis come from the year 2000 survey, though the information and results are compared across years to ensure consistency of the data. The variables used in this analysis describe the cost, design and operation of the cooling system, the capacity and performance of the associated generator(s) and the characteristics of the body of water from which the cooling system draws and into which it discharges water.

REAL INSTALLATION COSTS is the real installed cost of cooling system $i$ in thousands of dollars, adjusted for inflation using the Producer Price Index for the year of installation. ${ }^{4}$ (U.S. Council of Economic Advisors, 2008). Dummy variables are created for each type of cooling system, ONCE-THROUGH and RECIRCULATING. The once-through (recirculating) dummy variables take the value of one if the system is once-through (recirculating) and is zero otherwise. NATURAL is a dummy variable equal to one if the cooling system intakes water from a water body expected to have significant wildlife populations (lake, river, or ocean). It is zero if the water is taken from a well or municipal source. FLOWRATE is the design cooling water flow rate at 100 percent load at intake in cubic feet per second. MAXRATING is the nameplate rating of generator $\mathrm{j}$. These are summed for the generators associated with each cooling unit. MAXFLOW1 is the sum of the design flow rates in the condensers in cubic feet per second at 100 percent load for the generators served by cooling system i. TEMPERATURE INCREASE is the average design temperature rise in degrees Fahrenheit across the condenser at 100 percent

\footnotetext{
${ }^{4}$ Downloaded from the St. Louis Federal Reserve web site, http://research.stlouisfed.org/fred2/series/PPIACO/downloaddata?cid=31, 1982=100.
} 
load for generators associated with cooling system i. THERMAL VOLUME is the sum of the products of the maxflow and temprise variables for the generators served by cooling system $\mathrm{i}$. This is a measure of the total amount of cooling done by cooling system i. PLANT REGION dummy variables are created based on Census Bureau classifications of the U.S.

Variables used to test the impact of environmental policy on installation costs are discussed here. YEAR INSTALLED is the year in which the cooling system came on line and is used as a proxy for vintage of the system. CWA is a dummy variable which is equal to one if the cooling system was installed in 1974 or after and is zero if the cooling system was installed in the year 1973 or earlier. ${ }^{5}$ To test for the effect of the CWA on water cooling system installation costs, an interaction term of YEAR INSTALLED and CWA is calculated by multiplying the two variables together. Since the CWA expressed a preference for recirculating systems, an additional interaction term is created to test for a differential effect on installation costs between oncethrough and recirculating system after the CWA was in place. The variable is the product of the YEAR INSTALLED, CWA, and RECIRCULATING variables.

A list of summary statistics for the variables used in this analysis is given in Table I.

\section{Analysis}

A hedonic price model will be used to estimate the effects of vintage and regulatory policy on the cost of water cooling systems. The model assumes that the characteristics of the water cooling and generation system alter the price of the water cooling system. The estimation equation is given by:

\footnotetext{
${ }^{5}$ Robustness of the CWA variable, with the value of one starting in 1973, 1975, and 1976, were also used in the analysis. Given that water cooling systems, and power plants in general, are large investments that take multiple years to complete no CWA dummy starting in 1972 (the year the Act passed) is used.
} 
Where $C_{i}$ is the real installation costs of a cooling water system, $\alpha_{j}$ is a utility dummy variable, $X_{i}$ is a vector of cooling water system characteristics, $G_{j}$ is a vector of characteristics of the generator(s) with which the given cooling water system is paired, $T_{i}$ is the type of cooling water system (once-through or recirculating), $P_{i}$ is a vector of regulatory policy variables, and $R_{i}$ is a vector of regional dummy variables. The error terms are clustered on the utility to control for potential correlation between water cooling systems within the same utility. A Durbin-WuHausman endogenity test was performed to determine whether the choice of water cooling type (recirculating or once-through) is endogenous in the model. The test failed to reject the exogenity of the water cooling type. ${ }^{6}$

The policy and interaction terms' interpretation is complicated, thus a short discussion of this is warranted. The year installed variable shows whether performance-adjusted installation costs have fallen over time, which represents technological advancement in this model. The CWA dummy variable shows whether a one time change in real installation costs occurred when the CWA passed. The year installed CWA interaction term shows how the association of year installed with real installation costs was altered for systems installed after the CWA was passed. The year installed CWA recirculating interaction term shows how the association of year installed with real installation costs was altered for recirculating systems installed after the CWA was passed.

\section{Results and Discussion}

\footnotetext{
${ }^{6}$ Nonetheless, an instrumental variable estimation was also run to determine if the policy variables have the same sign and significance as those in Table II. The policy variables sign and significance are unchanged using the specification in Table 2, Column 1. Results are available from the authors by request.
} 
Table II, Column 1 shows the results of Ordinary Least Squares regressions of the model given in [1]. Column 2 and 3 show the robustness of the coefficients to different model specifications. Column 2 omits the utility dummy variables while Column 3 uses a natural log transformation for the dependent variable. Characteristics of the water cooling system have a robust association with real installation costs. The coefficient on recirculating systems is consistently positive and statistically significant, implying that they are more expensive to install than once-through systems. A larger generator rating is consistently positive and statistically significant. Other characteristic coefficients have the same sign but are not statistically significant in all estimations.

The evidence on technological advance over time comes from the installation year variable and its interactions. The results from Table II show no statistically significant advance previous to the CWA regulations. The interaction terms show that the passage of the CWA had no statistical effect on installation costs for the models that include a firm dummy. If the firm dummy is excluded, the passage is statistically associated with a one-time drop in costs and an increasing trend over time. The effect of CWA passage on recirculating system installation costs is for a decreasing and statistically significant trend over time in two of the three models. The result that installation costs have statistically fallen since the imposition of environmental policy in the form of a technology standard is uncommon. The theoretical prediction and empirical evidence points to technology standards leading to no reduction or an increase in costs over time.

The results given in Table II all assume that a change in the pattern of installation costs due to the CWA occurred in 1974. In order to determine whether this assumption is robust, model [1] was re-run with CWA dummies that assume a change in the years 1973, 1975, and 1976. Results of the robustness of the CWA specification are given in Table III. Using the year 1973 as a 
break point leads to the same results as when 1974 is used. Recirculating systems fell in installation costs after the CWA while once-through and both types pre-CWA had constant installation costs. However, if the CWA dummy starts in 1975 or 1976 then none of the policy variables are statistically significant. ${ }^{7}$ While these 1975 and 1976 CWA results show that the results concerning technological advance in recirculating systems are not robust, the specification assumes that a change in behavior occurred well after the CWA actually became law. In all, the results provide evidence that technology standards may not restrict technological advancement as much as past evidence suggest.

\section{Conclusion}

The theoretical predictions of the impact of technology standards on costs of pollution control equipment are well researched. They tend to show that technology standards are inferior instruments in encouraging technological advancement when compared with market-based instruments. The empirical evidence is generally consistent with this prediction; however most of the evidence comes from air pollution control equipment. This analysis extends the literature by providing evidence on the relationship between environmental policy instrument and technological advancement for water cooling systems.

The CWA essentially instituted a technology standard for recirculating water cooling systems at U.S. power plants. The ratio of once-through to recirculating water cooling systems reversed after passage of the CWA. A hedonic price model of water cooling systems is estimated here using year installed as a proxy for vintage. The results find that there was no statistical evidence of technological advancement previous to the CWA. After the CWA, recirculating systems have

\footnotetext{
${ }^{7}$ If a logged dependent variable is used with a 1975 CWA dummy variable, then the statistically significant negative coefficient for recirculating systems interacted with CWA dummy returns. Full regression results are available from the authors by request.
} 
shown a statistical reduction in installation costs over time while once-through systems have not. The result is robust to some specifications but not to altering the year that the CWA had an impact on installation costs. The result for recirculating systems after the CWA is a break from past evidence concerning the relationship between technological standards and technological advancement. 


\section{References}

Bellas, A. (1998). Empirical Evidence of Advances in Scrubber Technology. Resource and Energy Economics 20 (4); 327-343.

Bellas, A. and I. Lange. (2010). Technological Progress in Particulate Removal Equipment at U.S. Coal Burning Power Plants. Journal of Regulatory Economics 38(2), 180-192.

David, M. and B. Sinclair-Desgagne. (2005). Environmental Regulation and the Eco-Industry. Journal of Regulatory Economics 28(2); 141-155

Downing, P., and L. White. (1986). Innovation in Pollution Control. Journal of Environmental Economics and Management 13 (1); 18-29.

Electric Power Research Institute. (2004) Comparison of Alternate Cooling Technologies for U. S. Power Plants: Economic, Environmental, and Other Tradeoffs, 1005358.

Jaffee, A., R. Newell, and R. Stavins. (2002). Environmental Policy and Technological Change. Environmental and Resource Economics 22(1-2), 41-69.

Lange, I. and A. Bellas. (2005). Technological Change for Sulfur Dioxide Scrubbers Under Market-Based Regulation. Land Economics 81(4); 546-556.

Millman, S., and R. Prince. (1989). Firm Incentives to Promote Technological Change in Pollution Control. Journal of Environmental Economics and Management 17 (3); 247-265

Popp, D. (2003). Pollution Control Innovations and the Clean Air Act of 1990. Journal of Policy Analysis and Management 22 (4); 641-60.

Perino, G. (2010). Price Discrimination Based on Downstream Regulation: Evidence from the Market for SO2 Scrubbers. CCP Working paper 10-9.

Requate, T. and W. Unold. (2003). Environmental Incentives to Adopt Advanced Abatement Technology: Will the True Ranking Please Stand Up? European Economic Review 47(1), 125146.

Zerbe, R. (1970). Theoretical Efficiency in Pollution Control. Western Economic Journal 8 (4); 364-376 


\section{Table I: Summary Statistics}

\begin{tabular}{|l|l|l|l|l|l|}
\hline Summary Statistics & & & & & \\
\hline Sample & All Systems & Once-Through & Recirculating & Pre-CWA & Post-CWA \\
\hline Variable & & & & & \\
\hline Real Installation Costs (\$1000) & 7845 & 6635 & 9472 & 6859 & 11075 \\
& $(11723)$ & $(10469)$ & $(13112)$ & $(11703)$ & $(11217)$ \\
\hline Natural Water Body Intake & 0.85 & 0.98 & 0.67 & 0.86 & 0.81 \\
& $(0.35)$ & $(0.12)$ & $(0.46)$ & $(0.33)$ & $(0.38)$ \\
\hline Recirculating System & 0.41 & & & 0.29 & 0.80 \\
& $(0.49)$ & & & $(0.45)$ & $(0.39)$ \\
\hline Year Installed & 1964 & 1960 & 1970 & 1960 & 1980 \\
& $(12.03)$ & $(9.6)$ & $(12.6)$ & $(9.39)$ & $(4.8)$ \\
\hline Flow Rate Intake (Cubic ft/second) & 151.73 & 13.53 & 349.78 & 306.58 & 298.86 \\
& $(371.26)$ & $(84.9)$ & $(509.01)$ & $(410.39)$ & $(410.48)$ \\
\hline Maximum Generator Rating (MWh) & 356,115 & 313,873 & 416,009 & 292,944 & 574.079 \\
& $(336,308)$ & $(310,942)$ & $(362,237)$ & $(311,369)$ & $(327,569)$ \\
\hline Maximum Generator Flow Rate (Cubic ft/second) & 376.63 & 378.15 & 374.98 & 339.16 & 505.89 \\
& $(352.22)$ & $(383.05)$ & $(303.96)$ & $(351.77)$ & $(322.45)$ \\
\hline Design Generator Temperature Increase (F) & 18.72 & 17.35 & 20.72 & 17.69 & 22.28 \\
& $(5.74)$ & $(5.23)$ & $(5.78)$ & $(5.29)$ & $(5.80)$ \\
\hline Thermal Volume & 7060 & 6327 & 8113 & 5900 & 11068 \\
& $(6383)$ & $(5916)$ & $(6876)$ & $(5875)$ & $(6459)$ \\
\hline \hline Mean with Standard Deviation in Parenthesis & & & & & \\
\hline
\end{tabular}


Table II: Regression Results

\begin{tabular}{|c|c|c|c|}
\hline Dependent Variable: Real Installation Costs & & & \\
\hline Variable & & & \\
\hline Natural Water Body Intake & $2687^{*}$ & 1377 & 0.30 \\
\hline & $(1604)$ & $(938.32)$ & $(0.20)$ \\
\hline Recirculating System & $5248 * * *$ & $4111 * * *$ & $0.44 *$ \\
\hline & (1780) & (1102) & $(0.23)$ \\
\hline Clean Water Act Dummy & $\begin{array}{l}-304984 \\
(396111)\end{array}$ & $\begin{array}{l}-729218^{* *} \\
(309361)\end{array}$ & $\begin{array}{l}0.82 \\
(40.66)\end{array}$ \\
\hline Year Installed & $\begin{array}{l}-51.10 \\
(127.22)\end{array}$ & $\begin{array}{l}6.87 \\
(62.97)\end{array}$ & $\begin{array}{l}0.01 \\
(0.01)\end{array}$ \\
\hline Year Installed*Clean Water Act Dummy & $\begin{array}{l}155.61 \\
(200.80)\end{array}$ & $\begin{array}{l}368.05^{* *} \\
(156.69)\end{array}$ & $\begin{array}{l}-0.01 \\
(0.01)\end{array}$ \\
\hline Year Installed ${ }^{*}$ CWA* Recirculating & $\begin{array}{l}-2.34^{*} \\
(1.23)\end{array}$ & $\begin{array}{l}-1.07 \\
(1.07)\end{array}$ & $\begin{array}{l}-0.01 * * \\
(0.00)\end{array}$ \\
\hline Flow Rate Intake & $\begin{array}{l}6.89 * * * \\
(2.94)\end{array}$ & $\begin{array}{l}5.82 * * * \\
(2.14)\end{array}$ & $\begin{array}{l}0.01 \\
(0.01)\end{array}$ \\
\hline Maximum Generator Rating & $\begin{array}{l}0.02 * * * * \\
(0.00)\end{array}$ & $\begin{array}{l}0.02 * * * \\
(0.00)\end{array}$ & $\begin{array}{l}0.01 * * * \\
(0.00)\end{array}$ \\
\hline Maximum Generator Flow Rate & $\begin{array}{l}-16.0^{*} \\
(9.47)\end{array}$ & $\begin{array}{l}-14.60 * * \\
(6.55)\end{array}$ & $\begin{array}{l}-0.01 \\
(0.00)\end{array}$ \\
\hline Design Generator Temperature Increase & $\begin{array}{l}-136.05 \\
(151.60)\end{array}$ & $\begin{array}{l}-58.84 \\
(146.20)\end{array}$ & $\begin{array}{l}0.02 \\
(0.01)\end{array}$ \\
\hline Total Thermal Volume & $\begin{array}{l}0.63 \\
(0.41) \\
\end{array}$ & $\begin{array}{l}0.48 \\
(0.30) \\
\end{array}$ & $\begin{array}{l}0.01 \\
(0.01) \\
\end{array}$ \\
\hline Controls & $\begin{array}{l}\text { Utility \& } \\
\text { Region }\end{array}$ & Region & $\begin{array}{l}\text { Utility \& } \\
\text { Region }\end{array}$ \\
\hline Dependent Variable & Level & Level & Logs \\
\hline Observations & 1094 & 1094 & 1094 \\
\hline $\mathrm{R}^{2}$ & 0.46 & 0.29 & 0.6 \\
\hline
\end{tabular}


Table III: Robustness of CWA Dummy Specification

\begin{tabular}{|l|l|l|l|l|}
\hline \multicolumn{2}{|l|}{ Dependent Variable: Real Installation Costs } & & & \\
\hline CWA Switch Year & 1973 & 1974 & 1975 & 1976 \\
\hline Clean Water Act Dummy & -276346 & -304984 & -537130 & -363298 \\
& $(395390)$ & $(396111)$ & $(407255)$ & $(443033)$ \\
\hline Year Installed & -43.50 & -51.10 & -22.30 & -50.88 \\
& $(133.66)$ & $(127.22)$ & $(117.57)$ & $(112.74)$ \\
\hline Year Installed*Clean Water Act Dummy & 140.80 & 155.61 & 271.34 & 184.42 \\
& $(200.15)$ & $(200.80)$ & $(206.46)$ & $(224.41)$ \\
\hline Year Installed *CWA* Recirculating & $-2.01 *$ & $-2.34 *$ & -1.07 & -1.19 \\
& $(1.19)$ & $(1.23)$ & $(1.07)$ & $(1.33)$ \\
\hline \hline
\end{tabular}

$*$, **, *** indicates $10 \%, 5 \%$, and $1 \%$ significance, respectively, against a null of no effect

Other Controls: Natural Water Body Intake, Recirculating System, Flow Intake Rate, Maximum Generator Rating, Maximum Generator Flow Rate, Design Generator Temperature Increase, Total Thermal Volume, Utility Dummy, and Plant Region Dummy 